\title{
Proklamacje
}

\section{Dlaczego nie ma dziś Irzykowskiego?}

Włodzimierz Bolecki

TEKSTY DRUGIE 2018, NR 2, S. 392-400

DOI: $10.18318 /$ td.2018.2.24

arol Irzykowski - pisarz i krytyk - budzi fascynację Wśród znawców jego twórczości, ale poza nimi należy już chyba do coraz większego grona twórców, których nazwiska znane są tylko specjalistom'.

O kim zatem myślimy, kiedy zadajemy takie pytanie? Kogo szukamy? Nie chodzi przecież o kogokolwiek, o dowolnego pisarza. Nie pytamy wszak, dlaczego np. nie ma dziś Albina Dziekońskiego² czy Stefanii Zahorskiej³. Istnieje zatem coś wyjątkowego, coś, co intuicyjnie łączymy z nazwiskiem Karola Irzykowskiego i co powoduje, że

1 Wypowiedź w dyskusji podczas konferencji „Karol Irzykowski: człowiek sporu - postać sporna" (Paris Sorbonne - Uniwersytet Warszawski - IBL), w książce zbiorowej, która ukaże się w Wydawnictwie IBL.

2 Albin Dziekoński (1892-1940) - poeta, prawdopodobnie zginął w Katyniu.

3 Stefania Zahorska (1890-1971) - historyczka sztuki i pisarka, od 1939 r. na emigracji.
Włodzimierz Bolecki

(ur. 1952) - profesor w IBL PAN. Specjalizuje się w teorii i historii literatury, krytyce literackiej i edytorstwie. Ostatnio opublikował: Modalności modernizmu (2013), edycję krytyczną Pożegnania jesieni Witkacego (2014), Wenus z Drohobycza. O Brunonie Schulzu (2017). Autor prac nt. W. Berenta,

S.I Witkiewicza,

A. Wata, B. Schulza,

J. Mackiewicza,

W. Gombrowicza, G. Herlinga-Grudzińskiego. www.Bolecki.eu. 
pytanie to ma dla nas niekwestionowany sens, że wskazuje na jakiś poważny problem naszej współczesności.

O kogo i o co zatem pytamy, kiedy zadajemy pytanie: „Dlaczego nie ma Irzykowskiego?".

Po pierwsze, nie ma wątpliwości, że pytamy o autora Pałuby, czyli autora powieści, która wśród polskich literaturoznawców jest zgodnie uważana za matkę wszystkich eksperymentów w literaturze polskiej XX wieku. Patuba - utwór o formacie światowym, który swoją problematyką, rozwiązaniami narracyjnymi, kompozycyjnymi czy gatunkowymi wyprzedził o dziesięciolecia współczesne dyskusje na temat zagadnień metafikcji, deziluzji, paratekstów, na temat relacji tekst-komentarz, autor-bohater, na temat granic tekstu w literaturze, kryzysu języka, etyki formy literackiej i wielu innych. Nowatorstwo Irzykowskiego było tak wielkie, że Michał Głowiński w fundamentalnej książce o krytyce młodopolskiej, zatytułowanej Ekspresja i empatia, napisał o koncepcji krytyki literackiej Irzykowskiego: „nie w pełni mieściła się w tym stylu uprawiania, jaki w okresie Młodej Polski obowiązywal”" .

Po drugie, pytamy więc o krytyka, który do dziś pozostaje wzorem krytyki merytorycznej, mistrzem analizy, jednym z nielicznych twórców własnego systemu teoretycznoliterackiego i który był przez trzy dekady jednym z najważniejszych punktów odniesienia dla wszystkich współczesnych pisarzy i badaczy literatury - także w następnych pokoleniach (Janusz Sławiński, Ryszard Zengel, Tomasz Burek, Ewa Szary-Matywiecka, Wojciech Głowala, Ryszard Nycz, Henryk Markiewicz, Włodzimierz Bolecki, Kinga Siatkowska-Callebat, Mateusz Chmurski).

Po trzecie, Irzykowski - jak wszyscy wybitni moderniści - był oryginalnym myślicielem, a w wielu kwestiach po prostu nowatorem. Jako myśliciel Irzykowski okazał się bezwzględnym krytykiem wtórności, autorem niezwykle przenikliwych tez psychospołecznych dotyczących mechanizmów krążenia idei w kulturze oraz ich doskonałym diagnostą. Opisał np. plagiatowość przełomów literackich w Polsce, zjawisko, które do dziś jest rozpoznawalne w kulturze współczesnej. Był równocześnie nowatorskim psychologiem i antropologiem - i w tym zakresie także wybiegał daleko w przyszłość.

Po czwarte, ten myśliciel z kilkudziesięcioletnim wyprzedzeniem wprowadził do badań literatury kategorie etyczne i wypracował swoje własne kryterium etyki w literaturze, które nazwał kategorią szczerości.

4 M. Głowiński Ekspresja i empatia. Studia o młodopolskiej krytyce literackiej, Wydawnictwo Literackie, Kraków 1997. 
Po piąte, Irzykowski był pasjonatem z poczuciem misji - poświęcił literaturze całe swoje życie, czyli trzy dekady intensywnej aktywności pisarskiej. A przy tym nie tyle towarzyszył literaturze, co był jednym z najaktywniejszych krytyków, polemistów i komentatorów literackich idei przed 1939 rokiem. Można by je wszystkie zmieścić w jego własnej, doskonałej formule - „studia z literackiej teorii poznania”.

Literatura jako instrument poznawania, a krytyk jako twórca „teorii poznania" - to koncepcje, które w języku literaturoznawców ustabilizowały się dopiero kilkadziesiąt lat później.

Po szóste, Irzykowski to fenomen erudycji, szerokich i głębokich zainteresowań intelektualnych. Poruszał się wśród najważniejszych idei swej epoki - fascynowały go nauki społeczne i humanistyczne, filozofia, nauka i technika, literatura, teatr, film - trudno o szerszy zakres poszukiwań poznawczych w humanistyce.

Ale można też powiedzieć, że Irzykowski był intelektualnym samotnikiem. Od wszystkich, którzy brali udział w dyskusjach artystycznych czy intelektualnych, wymagał - podobnie jak Witkacy czy Gombrowicz - oryginalnej twórczości i nowatorstwa myśli. Bezwzględnie zwalczał wszelkie szablony - społeczne, artystyczne, językowe, grupowe i indywidualne. Walczył ze wszystkim, co uważał za intelektualną modę, bezrefleksyjne kopiowanie, zbiorowe fascynacje. Na każdym kroku walczył z tzw. myślą zbiorową, czyli indywidualną bezmyślnością, z podporządkowaniem hierarchii artystycznych zmiennym, chimerycznym i nieistotnym kryteriom środowiskowym, a właściwie - ich brakowi.

Nie uznawał żadnego mainstreamu. Przez trzydzieści lat, do roku 1939, polemizował z najważniejszymi pisarzami swojej epoki: m.in. z Brzozowskim, Przybyszewskim, Wyspiańskim, Witkacym, Boyem. Nikt z pisarzy nigdy nie otrzymywał od niego kredytu zaufania z powodu nazwiska czy tematu, wobec nikogo nie stosował „taryfy ulgowej”, a jeśli zgadzał się z pisarzami, akceptował ich utwory, to nigdy nie uprawiał krytyki panegirycznej lub promocyjnej. I mimo że przez całe życie komentował wydarzenia literackie, mimo że brał udział niemal we wszystkich ważnych dyskusjach o literaturze przed 1939 rokiem, to pisał nie po to, by utrwalać lub tworzyć wielkości, lecz by pokazywać artystyczne słabości utworów, ich wątpliwe rozwiązania artystyczne i intelektualne, niezrealizowane możliwości, niedomyślane pomysły, kalekie czy poronione wykonania. Demistyfikował, kwestionował, polemizował oraz - jakbyśmy dziś powiedzieli - dekonstruował; ustawiał się zawsze w opozycji do aktualnych mód i zbiorowych gustów. 
Przed rokiem 1939 znali go wszyscy pisarze i krytycy, a chociaż większość z nich propagowała zupełnie inne niż on koncepcje literatury, to jednak wszyscy z nim się liczyli. Irzykowski - nawet gdy pisał rzeczy, z którymi się nie zgadzano - był powszechnie słuchany; czytano go uważnie i poważnie. Był jednym z nielicznych w polskiej literaturze ponadpokoleniowym autorytetem.

Dlaczego więc go dziś nie ma?

Po pierwsze dlatego, że żyjemy w zupełnie innym (niż przed 1939 rokiem) świecie społecznym i politycznym, mamy do czynienia z zupełnie innym modelem kultury, ponieważ inna jest funkcja sztuki i literatury, ale też zupełnie inna jest funkcja mediów. A przede wszystkim - inni są odbiorcy i uczestnicy kultury. Czy potrzebny jest im Irzykowski? Z tego, co oni sami mówią o sobie - ani trochę.

Programem Irzykowskiego był „merytoryzm” - termin nie tylko dziś nieznany, ale przede wszystkim - nierozumiany.

Nierozumiany w świecie, w którym życiem kulturalnym rządzi wszechpotężny prasowy i medialny mainstream, w którym obowiązują etykiety, przynależność do grup, do koterii, do konkretnych mediów, środowisk, grup interesów; w świecie, w którym nie liczy się indywidualny głos, postawa, sąd, lecz wyrażanie zbiorowych opinii, oczywiście jakoś stylistycznie zindywidualizowanych, lecz aksjologicznie i poznawczo identycznych, a przede wszystkim - karnych wobec „przełożonych", jak żołnierze w postawie zasadniczej. Jest to więc świat, w którym krytyka jest pozbawiona oparcia w sobie, w indywidualnym głosie, osądzie, w jednostkowej pewności przeciw wszystkim - czyli w krytyce programowo niepoprawnej. To świat intelektualnych poprawności, świat masowego - ideologicznego i politycznego - rasizmu. To znaczy świat, w którym niepodważalną zasadą jest podział na swoich i obcych, na słusznych i niesłusznych, świat, w którym obowiązuje powszechnie akceptowany feudalizm hierarchii, wasalizm myśli, klientelizm relacji, w którym liczą się nazwiska, a nie dzieła. W takim świecie merytoryzm Irzykowskiego - z jego podstawowym hasłem "solidarności z autorem" - jest ciałem obcym. Obcym ciałem jest też zasada krytyki Irzykowskiego, według której należy najpierw autora i utwór dogłębnie zrozumieć, co nie znaczy akceptować, a dopiero później oceniać, by postępować wobec utworu lojalnie, dać mu kredyt rozumności i sensu, a dopiero potem podejmować krytykę czy polemikę.

Dla aksjologii Irzykowskiego, w której najważniejszymi kryteriami były oryginalność, nowatorstwo i intelektualna powaga (Witkacy nazywał ją „sprawami istotnymi”) nie ma miejsca w dzisiejszej, mainstremowej krytyce 
literackiej.W estetyce współczesnej akceptuje się - a nawet celebruje i propaguje - wtórność, permanentne kopiowanie, wykorzystywanie cudzych idei i pomysłów, a wszystko to w opakowaniu „ponowoczesności” i estetyki postmodernizmu. A ta z kolei ma dziś także konsekwencje dla Irzykowskiego niewyobrażalne - tzn. rozmywanie przedmiotu prawa autorskiego, czyli prawa do intelektualnej własności pomysłów, idei i ich sformułowań.

Dziś życiem kulturalnym - w którym nie ma miejsca dla Irzykowskiego rządzą, jak pisał Zbigniew Herbert, „logika parciana, pojęcia jak cepy, żadnej dystynkcji w rozumowaniu, brak koniunktiwu". Tytuł tego wiersza - Potęga smaku - doskonale pasuje do twórczości Irzykowskiego, bowiem smak, gust i intelekt są w niej największą potęgą ${ }^{5}$. Są „siłą bezsilnych”, by przywołać Ha$v a^{6}$. Dla Irzykowskiego taką siłą był merytoryzm, racjonalizm, do których żaden „new age” czy napuszona paplanina nie miałyby wstępu.

Dzisiejszymi, oficjalnymi hierarchiami artystycznymi rządzi dokładnie ta sama zasada, z którą Irzykowski walczył od początku swej drogi twórczej - „świętości nie szargać”. Tak jak w czasach Irzykowskiego, tak i dziś literacki e s t a bl i s h m e nt ma swoją zamkniętą listę nazwisk - przedmiot permanentnej adoracji, bezkrytycznych zachwytów i seryjnych nagród za cokolwiek. Tak jak w czasach Irzykowskiego, nie można szargać kanonizowanych na Parnasie świętości, ponieważ dzieło autora należącego do establishmentu musi być przedmiotem uwielbienia (nawet bez czytania). Pamiętamy sarkazm Gombrowicza: „dlaczego ma zachwycać, kiedy nie zachwyca?”. Autor Ferdydurke był wiernym uczniem Irzykowskiego (choć, jak zwykle, nigdy się do tego nie przyznał). Kto dziś pamięta młoda, debiutującą autorkę, która napisała, że nie zachwyca jej ostatni tomik Wisławy Szymborskiej ani książka Michała Pawła Markowskiego? Oskarżenia, które na nią spadły, że „niszczy autorytety", mogłyby konkurować z tsunami.

Ten świat, w którym nie ma Irzykowskiego, to świat pozbawiony autentycznej, niezależnej krytyki. To świat komisarzy estetycznych, którzy w opiniotwórczych miejscach życia literackiego pilnują, żeby nikt o „kanonizowanych na Parnasie" świętościach nie powiedział złego słowa. Dla Irzykowskiego była to rzecz niewyobrażalna. Każdy mógł polemizować z każdym, podziały ideologiczne były całkowicie wtórne, a nawet nieistotne wobec tego, co konkretny autor ma do powiedzenia. Kontekst polityczny nie definiował talentu ani oryginalności artystycznej czy myślowej. Krytyka Irzykowskiego

5 Pierwodruk w 1983 w Paryżu w tomie Raport z oblężonego miasta i inne wiersze (przyp. red.).

6 Chodzi tu o tytuł eseju Moc bezmocných, opublikowanego w 1978 roku (przyp. red.). 
to świadectwo i manifest wielości, różnorodności, barwności, oryginalności, słowem - indywidualności.

A co było dla Irzykowskiego oraz najwybitniejszych twórców jego generacji rzeczywistym, szanowanym "głównym nurtem"? Nauka. Tak, tak - nauka.

Nauka - rozumiana jako myśl współczesna, która rozwiązuje tajemnice świata i życia społecznego. Pisarz i krytyk musiał być partnerem dla uczonego. Irzykowskiego fascynowała psychologia, filozofia, zwłaszcza epistemologia (stąd jego „literacka teoria poznania”), antropologia, nauki społeczne. Przybyszewskiego fascynowała medycyna, którą studiował, podobnie jak później Jerzy Stempowski. Witkacy znał doskonale najnowsze prace z zakresu filozofii, antropologii, astronomii, matematyki, fizyki. Książeczka Gombrowicza Kurs filozofii w sześć godzin i kwadrans czytana jest przez studentów jako mini podręcznik. Berent, Parnicki i Stempowski studiowali historiografię, Bruno Schulz śledził uważnie odkrycia naukowe; Berent był ponadto doktorem nauk przyrodniczych (debiutował artykułami naukowymi). Mackiewicz był przyrodnikiem. Każdy z nich był późnym wnukiem poprzedniego pokolenia - realistów, pozytywistów, naturalistów, tych wszystkich premodernistów, pasjonatów rzetelnej wiedzy i nowoczesnej nauki.

Czy w dzisiejszym e s t a bl i s h m e n c i e literackim jest jakiś pisarz, który interesuje się nauką, filozofią, który w swojej twórczości podejmuje gorące tematy myśli współczesnej? Był jeden - Stanisław Lem. Jednak - mimo ogromnej popularności - to pisarz spoza mainstreamu. Zakwalifikowano go raz na zawsze jako science fiction writer, choć był filozofem współczesności. Podobnie jest z innymi pisarzami, którzy są pozycjonowani poza głównym nurtem dzisiejszego życia literackiego. np. Jacek Dukaj, Bronisław Wildstein, Antoni Libera, Elżbieta Cherezińska, Marta Kwaśnicka.

Dzisiejszy mainstream to intelektualne getto, w którym podstawową potrawą są wsobne problemy, tematy z drugiej ręki, krajowe wykonanie cudzych pomysłów - niczym licencjonowane programy telewizyjne. Kopie kopii, produkcje seryjne. A zamiast zainteresowania światem, rzeczywistością społeczną, kontemplacja zdeformowanego modernistycznego „ja”. Dla Irzykowskiego to wszystko były rzeczy niewyobrażalne, ponieważ napędzała go pasja naukowego poznania: ciekawość świata i człowieka. Dziś - być może - byłby kognitywistą.

Zmienił się gruntownie komunikacyjny model krytyki literackiej. W kulturze współczesnej nie ma tygodników literackich, które zastępowane są przez wkładki i dodatki poświęcone literaturze. Na recenzje książek nikt już nie czeka, ponieważ jeśli są nawet istotne i ważne, to chyba jedynie dla 
autorów, ich rodzin i ich znajomych. W czasach Irzykowskiego krytyka była indywidualną wypowiedzią o świecie, tworzyła wzorce jego rozumienia. I rozwijała się poza systemem poprawnościowych ograniczeń cenzuralnych.

Ta krytyka była powszechnie rozumiana jako działalność etyczna. Jeśli w literaturze jej miarą była szczerość, to w krytyce podkreślano jej godność. Wyznaczników takiej krytyki upatrywano w jej profesjonalizmie, na który składały się takie cechy jak pionierskość poszukiwań i rozwiązań artystycznych, permanentne tworzenie własnej terminologii, języka opisu i interpretacji, świadomość, że język jest narzędziem poznania, które bardzo łatwo zdeformować. Stąd u Irzykowskiego - i u jego duchowych spadkobierców uważna analiza semantyki pojęć, słów, poetyki tekstu i pryncypialne dyskusje nad każdym sformułowaniem.

Czytanie dziś tekstów Irzykowskiego to odświeżająca lektura. Uświadamia, jak wiele formuł jego autorstwa odnalazło swoje drugie życie w polszczyźnie. Na pozór znane z języka potocznego, wypełniły się nową treścią: czyn i słowo, walka o treść, słoń w składzie porcelany i wiele innych. Na przykład walka o treść - czyli walka o rzeczy najistotniejsze i najpoważniejsze.

Irzykowski plewił i karczował krytykę z małostkowości, ze spraw prywatnych, nieistotnych. A dla rozpleniającej się wtórności ukuł nawet sformułowanie „ludzie z drzwiami na plecach"7 czyli ci, którzy wyważają otwarte drzwi.

Irzykowski uczył krytycyzmu jako powinności intelektualnej. Jej instrumentami były dla niego kompetencja, jasność wypowiedzi, logika i bezinteresowność myśli. Odrzucał chodzenie w stadzie i kolektywizm opinii, traktowanej jako główny argument. Odrzucał wszelkie formy totalizmu i mętniactwa. I potrafił przyznać rację nawet największemu przeciwnikowi.

Nie ma dziś Irzykowskiego, chociaż pozostawił po sobie niewielkie i bardzo różnorodne grono kontynuatorów i pasjonatów: Sandauer, krakowska wielka krytyka (Błoński, Kijowski, Flaszen), a ze szkoły warszawskiej Burek i Sławiński. Ale może najbliżej dwoistej natury Irzykowskiego jako pisarza i krytyka byli Miłosz, Herling-Grudziński, Gombrowicz, Mackiewicz. Analizowali rzeczywistość za pomocą literatury i krytyki, a wszystko, co pisali, było kolejną realizacją „literackiej teorii poznania”.

7 Cf. „W oblężeniu”, Słoń wśród porcelany, pierwodruk 1934: „Kto są ci ludzie z drzwiami na plecach? To są pisarze polscy, którzy pasożytują na kwestiach już dawno załatwionych, rozbabrują je, eksploatują, udają bohaterski wysiłek. Nie tylko wywalili otwarte drzwi, ale nadto przemalowują je i zaopatrzywszy w nowy napis, urządzają za nimi swój kramik" (przyp. red.). 
Formacja Irzykowskiego już odeszła. Wychowana na pamięci o pluralistycznej, wielonarodowej, wielojęzycznej i wielokulturowej Rzeczypospolitej, a potem takiejż wielkiej emigracji wojennej. Formacja wychowana na twardych sporach ideowych, personalistycznych starciach indywidualności niechowających się za plecami redakcji, chlebodawców, wydawców, grup interesów $\mathrm{i}$ anonimowych macherów życia publicznego.

Karol Irzykowski był człowiekiem sporu i pozostał w pamięci potomnych jako postać sporna. A kto w dzisiejszym e s tabli s h m e n c i e literackim jest człowiekiem sporu lub postacią sporną - w tym najgłębszym sensie, jaki nadał mu Irzykowski? Rozglądam się wokół: nie widzę, nie słyszę, kto się wstrzymał? Cisza.

Nie ma Irzykowskiego - nie ma go wśród nas, gdyż dzisiaj nikt nie ma ochoty na samotność w literaturze i w sztuce. Dzisiaj mainstream zapewnia każdemu, kto się zgłosi, nagłośnienie i oświetlenie, przyprowadzi publiczność, zorganizuje nawet oklaski i bisy. W zamian żąda tylko jednego - identyfikacji z kolektywem. Tej ceny Irzykowski nigdy by nie zapłacił. 


\section{Abstract}

\section{Włodzimierz Bolecki}

THE INSTITUTE OF LITERARY RESEARCH OF THE POLISH ACADEMY OF SCIENCES (WARSAW)

Why is Irzykowski Missing?

Karol Irzykowski (1873-1944) was one of Poland's most important twentieth-century writers. His Pałuba (1903) is not only the earliest metafictional novel in Polish, but it can also be seen as the most radical prose experiment in European literature. As a literary, theatre and film critic, Irzykowski was respected for his originality, modern approach and principled stance. He set a benchmark for analytical thoroughness and fairness for decades to come. In recent years, however, interest in Irzykowski's work seems to have experienced a rapid decline in both literature and criticism. Bolecki suggests that today's literary culture and the mechanisms of the market have displaced the values on which the humanism of Irzykowski's era had been founded - values such as independent judgement, the quest for truth, respect for science, disinterestedness and an uncompromising attitude.

\section{Keywords}

Irzykowski, modernism, literary criticism, contemporary culture 